Revista de

Contabilidade e

Organizações

www.rco.usp.br
DOI: http://dx.doi.org/10.11606/rco.v8i22.55615
Journal of

Accounting and

Organizations

\title{
Desempenho acadêmico inferior dos alunos do "fundão": mito ou realidade?
}

\author{
Gilberto José Miranda ${ }^{\mathrm{a}}$, Jausson Monteiro Vicente ${ }^{\mathrm{b}}$, Sheizi Calheira de Freitas ${ }^{\mathrm{c}}$ \\ ${ }^{a}$ Universidade Federal de Uberlândia \\ ${ }^{b}$ Centro Universitário do Triângulo \\ 'Universidade Federal da Bahia
}

\section{Informações do Artigo}

Histórico do Artigo

Recebido: 15 de maio de 2013

Aceito: 16 de outubro de 2014

\section{Palavras chave}

Ensino

Ciências Contábeis

Egressos

Turma da Frente

Turma do Fundão

\begin{abstract}
Resumo
Internacionalmente, a relação e consequências da localização em sala de aula para o aprendizado e desempenho acadêmico discente vêm sendo estudadas com o fito de verificar a necessidade de adoção de estratégias de ensino ou ações voltadas para garantir o melhor aproveitamento da classe como um todo, independentemente da posição ocupada pelos discentes. Por sua vez, estudos brasileiros salientam o estereótipo negativo existente entre os alunos que se posicionam no fundo da sala. $\mathrm{Na}$ área contábil, o desempenho discente vem recebendo cada vez mais atenção em estudos científicos no Brasil, entretanto tais pesquisas ainda não enfocaram aspectos relacionados à ocupação do espaço em sala de aula. O presente trabalho teve como objetivo investigar, de forma exploratória, se existe correlação entre o desempenho discente no curso de Bacharelado em Ciências Contábeis e a localização escolhida pelos discentes em sala de aula. Para atingir esse objetivo foram utilizadas duas técnicas estatísticas, Teste t e Regressão Múltipla, em dados coletados a partir de um questionário elaborado para esse fim e aplicado a uma amostra de 102 alunos e egressos de uma instituição de ensino superior brasileira. Os testes revelaram que se sentar mais próximo do docente na sala de aula apresentou uma correlação positiva com o desempenho acadêmico dos discentes, ou seja, a "turma da frente" apresentou melhor Coeficiente de Rendimento Acadêmico (CRA) que a "turma do fundão". Esse resultado sugere a necessidade de atenção especial aos alunos que se sentam ao fundo da sala, bem como à formação dos docentes para lidar com essa situação. Além disso, os resultados apontam para a necessidade de realização de pesquisas sobre as causas e consequências para o aprendizado da ocupação dos diferentes espaços da sala de aula pelos discentes dos cursos de Ciências Contábeis.
\end{abstract}

Copyright (C) 2014 FEA-RP/USP. Todos os direitos reservados

\section{INTRODUÇÃO}

O desempenho dos alunos do curso de Ciências Contábeis vem despertando vários estudos no Brasil, nos últimos tempos (Moraes \& Araujo, 2012; Miranda, Casa Nova \& Cornacchione, 2012; Silva, Ranciaro Neto, Anjos \& Miranda, 2012; Silva, Gomes \& Guimarães, 2008; Souza, 2008; Peleias, Silva, Segreti, \& Chirotto, 2007; Lousada \& Martins, 2005). O alinhamento da Contabilidade brasileira aos moldes das normas internacionais e a procura significativa pelo curso de Ciências Contábeis explicam a preocupação com o desempenho acadêmico desses alunos em nosso país.

Autor Correspondente: Tel +55 34 3239-4176

E-mail : gilbertojm@facic.ufu.br (G. J. Miranda); jausson@hotmail.com (J. M. Vicente); shecal@ufba.br (S. C. Freitas)

UFU - Faculdade de Ciências Contábeis - Av. João Naves de Ávila, 2.121 Campus Santa Mônica - Bloco F - Santa Mônica - 38400-902 - Uberlandia - MG, Brasil
Dados do Censo Nacional de Educação Superior de 2010 apontam que o curso de Ciências Contábeis é um dos maiores do país em número de cursos de graduação, ficando atrás apenas de Administração, Pedagogia e Direito. Em 2010, o número de cursos chegou a 1080, representando $3,7 \%$ do total de cursos em 2010, com 265.164 matrículas, perfazendo $4,2 \%$ do total de matrículas no ensino superior.

Esse significativo número de alunos interessados na formação em Ciências Contábeis e a grande oferta do curso pelas instituições privadas, aliados às mudanças ocorridas no cenário contábil brasileiro, não se refletem na melhora do aproveitamento dos alunos dos cursos de Ciências Contábeis no país. Estatísticas do Conselho Federal de Contabilidade [CFC] (2012) indicam que o índice geral de aprovação no primeiro exame de suficiência de 2012, entre candidatos bacharéis em Ciências Contábeis, foi de 40,46\%, e, entre os técnicos, esse índice ficou em 30,89\%. Os números demonstram que grande parte dos alunos egressos dos cursos de Ciências Contábeis não está assimilando o mínimo 
de conhecimento necessário para exercer a profissão contábil, ou seja, cerca de $60 \%$ dos formandos em Ciências Contábeis não estão aptos ao pleno exercício de suas funções, de acordo com as estatísticas do Conselho Federal de Contabilidade.

Muitas pesquisas têm sido realizadas com a intenção de mapear variáveis relacionadas ao desempenho discente, seja no contexto do ensino superior de modo geral, seja no âmbito dos cursos de Ciências Contábeis (Lousada \& Martins, 2005; Alves, Corrar \& Slomski, 2008; Miranda, 2011) deve ser alterada para (Lousada \& Martins, 2005; Alves, Corrar \& Slomski, 2004; Miranda, 2011). Uma variável que pode estar associada ao desempenho discente, mas que ainda não foi pesquisada para os cursos de Ciências Contábeis no Brasil, de acordo com a literatura consultada, é a localização escolhida pelo aluno em sala de aula. Não se sabe se a ocupação do espaço da sala de aula pelos discentes do curso de Ciências Contábeis interfere na relação pedagógica entre professores e alunos e, consequentemente, no desempenho acadêmico.

Dessa forma, o problema desta investigação pode ser expresso na seguinte questão: existe associação entre o desempenho discente no curso de Bacharelado em Ciências Contábeis e a localização escolhida por esses discentes em sala de aula? Como proxy de desempenho discente será utilizado o Coeficiente de Rendimento Acadêmico (CRA).

Pesquisas anteriores desenvolvidas internacionalmente vêm se dedicando ao estudo dos impactos da localização de preferência dos alunos em seu desempenho e comportamento em classe (Stires, 1980; Montello, 1988); outras têm verificado os aspectos motivadores das escolhas por determinadas localizações em sala de aula (Totusek \& Staton-Spicer, 1982; Pedersen, 1994; Kaya \& Burgess, 2007).

Considerando que a localização em classe pode estar associada ao desempenho dos estudantes, o presente estudo espera contribuir diretamente para o melhor entendimento acerca dos aspectos relacionados à composição do desempenho discente na área de Ciências Contábeis no Brasil. Avalia-se se a propalada ideia de que "a turma de trás" ou "alunos do fundão" apresentam desempenhos inferiores à "turma da frente" se constitui em mito ou realidade.

Através dos resultados deste estudo, será possível, ainda, orientar estratégias pedagógicas voltadas à maximização do aprendizado, na medida em que os resultados possam revelar a necessidade de maior atenção a um grupo específico de estudantes que possuem como característica comum o espaço em que preferem se posicionar dentro da sala de aula.

\section{REFERENCIAL TEÓRICO}

\subsection{O ensino de Ciências Contábeis no Brasil}

Durante muito tempo, o papel do contador ficou restrito ao desempenho de meros registros. Esse profissional era visto apenas como um simples guarda-livros, porém a dinâmica socioeconômica e as transformações no mundo empresarial e na sociedade fizeram com que o contador reavaliasse as suas práticas, como salientam Figueiredo e Fabri (2000), e também os seus objetivos, em uma perspectiva mais ampla.

Segundo Peleias et al. (2007, p. 21), o Parecer CNE/CES no 289/2003 e a Resolução CNE/CES n ${ }^{\circ}$ 10/2004 "propugnam a formação de profissionais dotados de competências profissionais que reflitam a heterogeneidade das demandas sociais". Cardoso, Demuner e Batista (2006, p. 2) entendem que "o próprio plano de estudos do ISAR/UNCTAD juntamente com as Diretrizes Curriculares para os cursos de Ciências Contábeis apontam para uma formação interdisciplinar". Laffin (2005), por sua vez, destaca que a sociedade capitalista requer um profissional que seja polivalente e de aprendizagens multi e interdisciplinares, com competências para a análise e percepção frente à sociedade tecnológica.

O ensino superior deve proporcionar ao aluno um conjunto de competências para a sua inserção no mercado de trabalho. Como exemplos de tais competências, acompanhando as análises de Paiva (1993), podem-se citar: (a) imaginação na busca de soluções para problemas novos e inesperados; (b) capacidade de raciocinar logicamente sobre conteúdos simbólicos; (c) capacidade de compreender e de desenvolver os conhecimentos científicos; (d) compreensão do processo produtivo como um todo; (e) capacidade de avaliar as tendências de mudanças na sociedade, na cultura, na política, no mercado etc.; (f) precisão e adequação nas formas de comunicação escrita, oral e visual; $(\mathrm{g})$ capacidade de desempenhar múltiplos papéis profissionais e de adaptação rápida às novas gerações de equipamentos e ferramentas; (h) responsabilidade, compromisso e persistência na busca dos objetivos projetados; e (i) pensamento crítico e envolvimento ético na busca de soluções para os problemas sociais, do meio ambiente e em defesa dos direitos humanos dentro e fora do local de trabalho.

Diversos fatores podem influenciar o desempenho educacional e a aprendizagem de um estudante, porém, segundo Waiselfisz (2000, p. 27), “[...] grande parte das discussões sobre a qualidade educacional centra-se no tema da docência". O autor afirma ainda que o debate sobre as possíveis relações entre a qualidade da docência e os resultados do ensino é relativamente antigo, com uma grande massa de estudos que se concentra, especialmente, na segunda metade das décadas de 1960 e 1970.

$\mathrm{O}$ significativo número de alunos interessados na formação em Ciências Contábeis e a grande oferta do curso pelas instituições privadas, bem como as mudanças ocorridas no cenário contábil brasileiro, não se refletem na melhora do aproveitamento dos alunos. Estatísticas do CFC (2012) indicam que o índice geral de aprovação no primeiro exame de suficiência de 2012 dos candidatos 
bacharéis em Ciências Contábeis foi de 40,46\%. No ano de 2011, os dados consolidados demonstraram que 32.950 candidatos bacharéis em Ciências Contábeis fizeram o exame de suficiência; desses, apenas 14.255 foram aprovados no exame, ou seja, $43,26 \%$ do total. A Tabela 1 apresenta os resultados, por região, no que diz respeito ao primeiro exame de suficiência do ano de 2011.

Tabela 1. Resultado do Exame de Suficiência por Região

\begin{tabular}{lcc}
\hline & REGIÃ0 & \multicolumn{2}{c}{ APROVADOS REPROVADOS } \\
\hline Regĩão Norte & $13,01 \%$ & $86,99 \%$ \\
\hline Regĩã Sudeste & $34,51 \%$ & $65,50 \%$ \\
\hline Regĩão Sul & $36,82 \%$ & $63,18 \%$ \\
\hline Regãa Nordeste & $28,25 \%$ & $71,75 \%$ \\
\hline Regĩã Centro-Oeste & $25,43 \%$ & $74,57 \%$ \\
\hline
\end{tabular}

Fonte: Conselho Federal de Contabilidade (2012)

Pelos dados do CFC (2012), pode-se perceber que a região Norte apresentou os piores resultados, com apenas $13,01 \%$ dos candidatos aprovados, enquanto que a região Sul apresentou o melhor desempenho, com $36,82 \%$ de aprovação.

Os números da Tabela 1 também demonstram que grande parte dos alunos egressos dos cursos de Ciências Contábeis não está conseguindo o mínimo de conhecimento necessário para exercer a profissão contábil, ou seja, de acordo com os dados de 2011, cerca de $60 \%$ dos egressos em Ciências Contábeis não estão aptos ao pleno exercício de suas funções.

Para Iudícibus e Marion (2002, p. 43), “a tarefa básica do contador é produzir e/ou gerenciar informações úteis aos usuários da contabilidade para as tomadas de decisões". Para satisfazer tais exigências, o recémformado deve compreender e dominar as técnicas contábeis, bem como ser capaz de dispor de uma visão global e crítica do ambiente no qual está inserido.

Silva, Gomes e Guimarães (2008) analisaram o desempenho dos estudantes de Ciências Contábeis submetidos ao ENADE/2006. O resultado da pesquisa demonstrou que os alunos não possuem o hábito da leitura, o que, segundo os autores, explica o baixo desempenho dos estudantes de Ciências Contábeis nas questões discursivas do exame.

Souza (2008) tentou identificar, em seu estudo, a relação entre o desempenho dos alunos do curso de Ciências Contábeis e sua situação socioeconômica. Os resultados indicaram que a formação do aluno antes do ingresso no curso é a variável de maior influência no desempenho dos cursos. Em seguida, estão a escolaridade dos pais, o esforço pessoal no curso e a renda familiar como as variáveis mais influentes no modelo desenvolvido.

Miranda, Casa Nova e Cornacchione Jr. (2012) investigaram as relações entre o desempenho discente e a qualificação docente. Os resultados indicaram que os cursos que apresentaram os melhores resultados na avaliação ENADE de alunos concluintes são aqueles que possuem, também, os maiores níveis de qualificação acadêmica do quadro docente.

Bernardo, Nascimento e Nazareth (2010) tentaram, em seu trabalho, identificar características relacionadas ao ensino, pesquisa, práticas interdisciplinares e suas inter-relações nos cursos de Ciências Contábeis no estado de Minas Gerais. Os resultados apontaram para a predominância dos cursos noturnos e o fato de que os discentes estão fortemente inseridos no mercado de trabalho, sendo esses dois fatores limitadores do desenvolvimento de pesquisas. O estudo também demonstrou que as práticas interdisciplinares têm relação estreita com a atualização das grades curriculares e com as ofertas das disciplinas de Controladoria e Contabilidade Internacional.

Silva et al. (2012) buscaram avaliar se o uso de redes sociais pode ser relacionado ao desempenho acadêmico de estudantes de graduação em contabilidade. Os resultados demonstraram que não há como afirmar, com base na amostra analisada no estudo, que o uso das redes sociais impacta o desempenho acadêmico dos estudantes.

Nesse contexto, em que o estudo do desempenho acadêmico ganha espaço na academia, e a contabilidade brasileira passa por significativas transformações, destaca-se a importância de se analisar o desempenho dos estudantes matriculados nos cursos de Ciências Contábeis no Brasil. Embora seja senso comum a ideia de que os alunos que se sentam no fundo da sala de aula tenham desempenho acadêmico inferior àqueles que se sentam na frente, nenhum estudo foi realizado, ainda, com a finalidade de investigar tal associação nos cursos de Ciências Contábeis brasileiros.

\subsection{A localização dos discentes em classe e seu impacto no desempenho}

Estudos voltados à localização dos discentes em classe são mais comuns nas áreas de educação e psicologia. Entretanto, as possíveis consequências das escolhas dos estudantes no que tange ao local de preferência para assistirem às aulas podem ser observadas nas mais diversas áreas do conhecimento.

Quando se trata do tema localização em sala de aula, os trabalhos, comumente, focam aspectos como motivação e personalidade para justificar o processo de escolha das posições em sala de aula, como pode ser observado nos estudos desenvolvidos por Pedersen (1994) e Kaya e Burgess (2007). Pedersen (1994) afirma que a escolha da posição em sala de aula realizada pelos discentes não é aleatória, e que um conjunto de fatores situacionais e pessoais, possivelmente, afetam essa escolha, sendo provável que tal escolha interfira nas interações entre estudantes, na sua participação em aula e no seu desempenho. Por outro lado, Kaya e Burgess (2007) estudaram o comportamento dos discentes no que 
se refere à escolha do local na sala de aula. Os autores concluíram que os estudantes que preferem as posições ao fundo da sala tendem a ter mais sentido de propriedade sobre tais locais do que aqueles que preferem outras localizações, tendo demonstrado as mulheres maior senso de propriedade sobre determinada localização em sala de aula do que os homens.

Adicionalmente, a relação entre desempenho e localização em sala de aula também tem sido explorada na literatura, como ocorre nos trabalhos de Stires (1980) e Montello (1988). Stires (1980) encontrou evidências de que os discentes que podem optar pelo local em que se sentam para assistirem às aulas alcançam melhor desempenho acadêmico, e que estudantes cuja preferência é o centro da sala de aula apresentaram maiores notas do que aqueles que preferem as laterais. Entretanto, Montello (1988) não encontrou resultados sugerindo a relação entre escolha da localização e desempenho. $\mathrm{O}$ autor afirma que evidências empíricas apontam para a existência de relação entre a localização na sala de aula e a participação dos alunos nas aulas, bem como suas atitudes frente ao curso. Já com relação ao desempenho, Montello (1988) declara que, se houve alguma relação, ela se mostrou muito fraca e, portanto, não foi considerada.

Impende salientar que os estudos acima revisados foram realizados internacionalmente e, por isso, tornase relevante saber quais resultados serão encontrados a partir da análise da estrutura acadêmica brasileira. Embora não tenham sido localizados muitos estudos que abordassem o tema no Brasil, está claro na literatura pesquisada a tendência de estereotipagem negativa, por parte de professores e alunos, quanto aos estudantes que ocupam as últimas filas da sala de aula.

Para Dayrell (2007, p. 15), a “turma de trás" é estereotipada como sendo a turma da bagunça. Nesse sentido, os resultados do estudo de Vieira e Maciel (2009, p. 11) apontaram que o "o preconceito que margeia os alunos do 'fundão' apresenta-se de modo vulgarizado no dia-a-dia da sala de aula. Desse modo é convertido em algo banal, cristalizando-se e não sendo percebido tanto pelos alunos quanto pelos professores". De fato, não é raro encontrar passagens na literatura que evidenciam tal comportamento. Freitas, Ferreira e Ustra (2011, p. 9) deixam isso claro em seu trabalho ao afirmarem que obtiveram "uma grande participação de todos, principalmente dos alunos do "fundão", demonstrando que a expectativa em relação a esses alunos não era positiva. No trabalho de Silva (2006, p. 131), nota-se a percepção dos docentes em relação a esses alunos, quando o autor menciona que "os professores consideram os alunos que sentam no fundão como descompromissados e desordeiros". Vieira e Maciel (2009, p. 15), em seu estudo de campo realizado em uma escola pública no município de Maringá, perceberam que alguns professores "demonstravam certa indisposição em relação aos alunos que estavam sentados no fundo da sala. As aulas, invariavelmente, eram direcionadas aos alunos localizados nas primeiras carteiras, próximos do espaço ocupado pelos professores". Ainda de acordo com as autoras,
(...) é como se na escala de classificação (implicitamente presente em sala de aula) o aluno da frente possuísse as virtudes requisitadas pela instituição escolar, ocupando então uma posição "superior" na referida escala, enquanto aquele aluno situando no fundo, distante do professor, da vigilância quanto ao cumprimento das regras, enfim das virtudes demandadas pela escola, ocupasse uma posição "inferior" na classificação escolar (Vieira \& Maciel, 2009, p. 18).

Reforçando esse entendimento, Brandão (1986, p.107) afirma que era frequentador da "turma de trás" nas salas de aula e que, portanto, era "um usuário também das antigas expulsões de classe, das listas de suspensão, dos candidatos costumeiros a 'conversas com o diretor', do 'pessoal da segunda época' e dos eventuais reprovados". Brandão cita inúmeras peripécias da "turma de trás", valendo a pena, a título de curiosidade, citar uma dessas:

\begin{abstract}
Antes da aula de um professor de Matemática (de resto, conhecidíssimo), a primeira do dia, os alunos introduziram por um portão de trás do pátio do colégio, um burro. Conseguiram a custo colocá-lo no centro da sala de aula, no círculo que abriram com o empurrar das carteiras. Ficaram espiando os acontecimentos futuros pelas frestas de janelas fechadas. O professor veio, viu o que havia. Se se espantou, disfarçou. Fez a chamada como de costume, escreveu no quadro negro a síntese da matéria e deu a aula inteira, palavra por palavra. Terminada, virou-se para $\mathrm{o}$ atento animal a quem dirigiu o ensino, todo o tempo, e disse: "agora você vai e avisa seus colegas que a aula de hoje é matéria para a prova de amanhã”. (Brandão, 1986, p. 18).
\end{abstract}

Esses relatos apresentam pistas quanto ao preconceito com a "turma do fundão", bem como suas possíveis causas. Ainda, sinalizam para uma divisão clara da sala da aula em duas partes, de acordo com Brandão (1986, p. 112), em alguns colégios de seu tempo de estudante: “os 'bons alunos' eram convocados à esfera olímpica da intimidade com o professor e os 'outros' eram forçados a distribuírem-se da metade para trás", o que reforça a ideia de "turma da frente" e "turma de trás".

Diante do exposto, este trabalho buscou evidências sobre as consequências da localização discente em sala de aula, considerando a sua divisão em duas áreas: a frente e o "fundão", como será explicitado no tópico a seguir.

\section{ASPECTOS METODOLÓGICOS}

Esta pesquisa possui caráter exploratório e objetivou verificar a existência de correlação entre a localização escolhida pelos discentes em sala de aula e o seu desempenho acadêmico. Para tanto, foram empregados testes de diferença de médias, Teste $t$, e uma Análise de Regressão, utilizando-se o estimador de Mínimos Quadrados Ordinários (MQO). O estimador MQO foi escolhido por ser amplamente reconhecido como o melhor estimador linear não enviesado (Kennedy, 2008).

Através do Teste $t$ de diferença de médias, procurouse verificar se as médias dos estudantes que optam pela 
localização mais próxima do professor, denominados, neste trabalho, de "turma da frente", apresentavam desempenho acadêmico estatisticamente diferente daqueles que optam pela localização mais distante do docente, aqui denominados de "turma do fundão". O referido teste foi escolhido devido às características dos dados, a saber: duas amostras independentes que não possuem variância populacional conhecida (Field, 2009; King, Rosopa \& Minium, 2011).

Em seguida, realizou-se uma Análise de Regressão para estudar o comportamento do desempenho dos estudantes para cada nível de proximidade do docente em que preferiam se sentar, sendo esse nível identificado pela localização da fileira de cadeiras na sala de aula. Cada fileira foi representada na regressão por uma variável dummy, cuja variável dependente foi o desempenho acadêmico dos discentes. A regressão múltipla aplicada obedeceu ao modelo geral de regressão, conforme apresentado em Kennedy (2008).

Adicionalmente, realizou-se uma análise descritiva, objetivando conhecer a percepção dos discentes quanto a aspectos relacionados às suas escolhas por determinadas localizações em sala de aula, bem como possíveis justificativas ou principais motivações para a opção por uma determinada localização.

Os dados foram coletados, utilizando-se o levantamento por meio da aplicação de questionário aos alunos de final de curso e egressos do Bacharelado em Ciências Contábeis de uma universidade pública brasileira, nos meses de novembro e dezembro de 2012. Entre as perguntas que compunham o questionário, destacam-se as informações demográficas, como a idade e a situação junto ao mercado de trabalho, além de um mapa (Figura 1) que reproduzia uma sala de aula da instituição em que o estudo foi realizado, no qual os discentes deveriam apontar a localização em que se sentavam com maior frequência ao longo do curso. As três primeiras fileiras foram consideradas como "frente" da sala e as três últimas foram consideradas como "fundo" da sala. O referido questionário foi aplicado em sala de aula para os alunos do último ano e enviado por e-mail aos egressos.

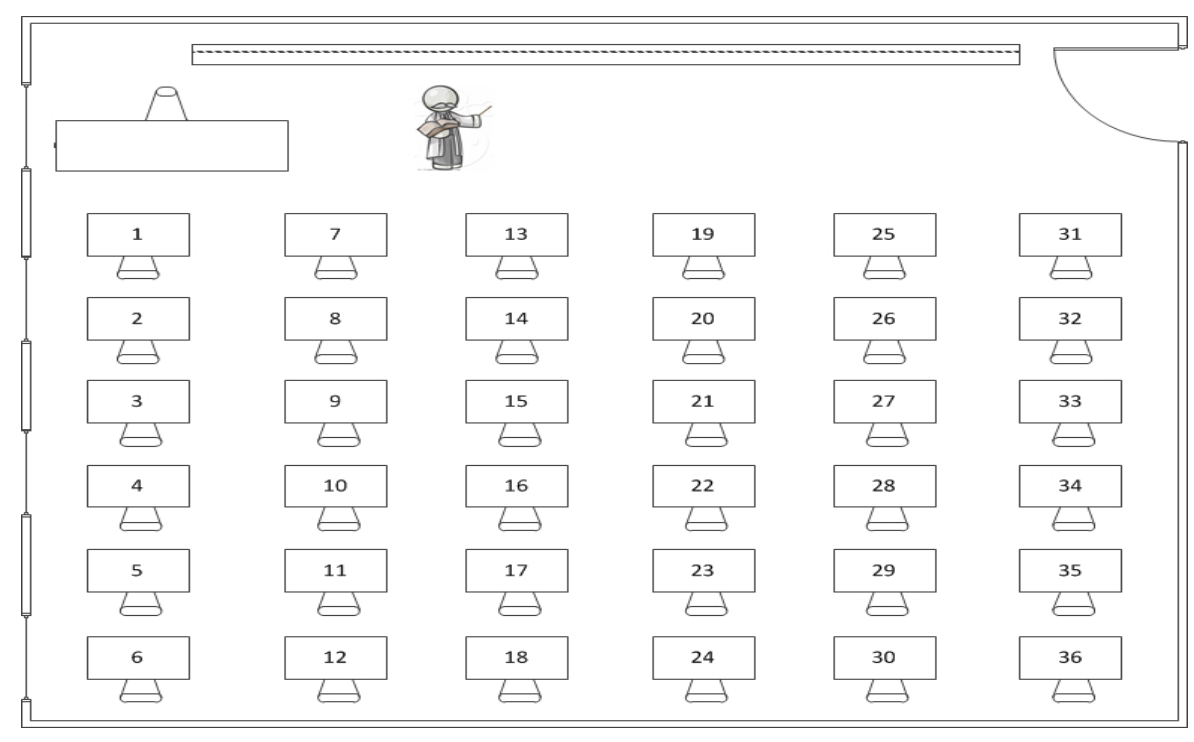

Figura 1. Sala de aula

Faz-se necessário salientar que no presente estudo foi utilizado como proxy de desempenho acadêmico o Coeficiente de Rendimento Acadêmico - CRA constante em uma resolução do Conselho de Graduação da IES. A seguir, descreve-se a fórmula para o cálculo do CRA:

$$
\text { CRA }=\frac{\sum\left(\operatorname{Nota} \times \mathrm{CH}_{\underline{c}}\right)}{\sum \mathrm{CH}_{\mathrm{m}}} \times 1-\frac{1 \sum \mathrm{CH}_{\mathrm{rf}}}{2 \sum \mathrm{CH}_{\mathrm{m}}}
$$

Onde:

$\mathrm{CH}_{c}$ : carga horária cursada (componentes curriculares cursados com aprovação e componentes curriculares cursados com reprovação);

$\mathrm{CH}_{\mathrm{m}}$ : carga horária matriculada (componentes curriculares cursados com aprovação, componentes curriculares cursados com reprovação e componentes curriculares com trancamento parcial);

$\mathrm{CH}_{\text {rf: }}$ carga horária em componentes curriculares com reprovação por frequência.

O CRA foi obtido mediante consulta ao histórico acadêmico dos participantes da pesquisa, por autorização obtida quando aceitaram participar da pesquisa. 


\section{ANÁLISE DOS RESULTADOS}

\subsection{Caracterização dos Respondentes}

A caracterização dos respondentes contida nesta seção é pertinente para as fases posteriores do trabalho, pois permite traçar um perfil da amostra em questão, possibilitando estudar as condições em que as variáveis se associam.

A pesquisa foi realizada com alunos de final de curso e ex-alunos do Bacharelado em Ciências Contábeis de uma instituição pública de ensino superior brasileira. A amostra totalizou 102 respondentes (questionários completos), dos quais $65,7 \%$ têm até 30 anos de idade, sendo essa a faixa etária predominante na amostra pesquisada.

Entre os respondentes, 49\%, ou seja, 50 indivíduos não trabalham na área contábil, enquanto que $52 \%$ da amostra (52 respondentes) trabalham, seguindo a tendência de que a maioria dos alunos que optam por cursar Ciências
Contábeis consegue colocação no mercado de trabalho em atividades relacionadas à Contabilidade.

Com relação à escolaridade, tem-se que: 20,6\% da amostra concluíram a graduação; 30,4\% cursaram especialização MBA; 3,9\% têm o título de mestre; e $45,1 \%$ ainda estão no quarto ano da graduação. Do total de respondentes, 61,8\% (63 indivíduos) ainda não possuem registro no Conselho Regional de Contabilidade.

Adicionalmente, apresentam-se as seguintes percepções acerca do grau de dificuldade do curso de graduação em Ciências Contábeis coletadas através do questionário de pesquisa: 52 respondentes $(51 \%)$ consideraram ou consideram o curso difícil; 48 (47,1\%) responderam que consideram o curso fácil; e apenas dois $(2 \%)$ classificaram o curso como muito fácil.

Por fim, no que se refere ao desempenho acadêmico dos respondentes, tem-se que: o menor CRA entre os participantes da pesquisa foi igual a 59,68; o maior foi igual a 94,62 ; o CRA médio entre os pesquisados foi igual a 79,57; e o desvio padrão foi 7,86. A Tabelax 2 evidencia a média por localização indicada pelos respondentes:

Tabela 2. Sala de aula com média CRA por carteira

\begin{tabular}{|c|c|c|c|c|c|}
\hline 1 & 7 & 13 & 19 & 25 & 31 \\
\hline 91,8 & 77,5 & 80,1 & 79,0 & 73,5 & $*$ \\
\hline 2 & 8 & 14 & 20 & 26 & 32 \\
\hline 84,6 & 84,4 & 81,7 & 85,9 & 79,8 & 76,7 \\
\hline 3 & 9 & 15 & 21 & 27 & 33 \\
\hline 80,9 & 81,7 & 79,2 & 79,0 & 82,2 & 80,3 \\
\hline 4 & 10 & 16 & 22 & 28 & 34 \\
\hline 77,69 & 81,8 & 71,5 & 76,6 & $*$ & 75,6 \\
\hline 5 & 11 & 17 & 23 & 29 & 35 \\
\hline$*$ & 78,0 & 74,3 & $*$ & 80,8 & $*$ \\
\hline 6 & 12 & 18 & 24 & 30 & 36 \\
\hline$*$ & 78,3 & 76,8 & 81,0 & 71,4 &  \\
\hline
\end{tabular}

(*) Carteiras não apontadas pelos estudantes e egressos 
Como podem ser observadas na Figura 2, as médias sugerem a existência de uma diferença entre os CRAs dos estudantes que ocupavam as posições mais à frente da classe, que são médias superiores quando comparados aos CRAs obtidos pelos discentes que afirmaram ter preferência pelo posicionamento mais ao fundo da classe e, portanto, mais distantes do professor (é curioso notar que a carteira que possui a maior média CRA é a carteira de número "1", aquela que está posicionada em frente à mesa do professor, conforme Figura 1). A existência ou não de significância estatística na diferença observada nas médias entre os dois grupos será testada a seguir.

\subsection{Teste $t$}

A primeira análise realizada neste trabalho testou a significância estatística da diferença entre os CRAs médios dos alunos da "turma da frente" e da "turma do fundão". Para tanto, cada respondente foi alocado para um dos dois grupos, conforme a localização preferencial em sala de aula apontada por eles no questionário de pesquisa. Consequentemente, duas amostras independentes foram geradas, possuindo, a primeira, 65 sujeitos, grupo 1, correspondente à "turma da frente", e a segunda, com 37 sujeitos, grupo 2, correspondente à "turma do fundão". A Tabela 3 apresenta as estatísticas descritivas dos dois grupos:

Tabela 3. Estatísticas descritivas por grupo de estudantes

\begin{tabular}{cccc}
\hline Grupo & $\begin{array}{c}\text { Número de } \\
\text { Elementos }\end{array}$ & CRA Médio & $\begin{array}{c}\text { Desvio Padrão } \\
\text { (CRA) }\end{array}$ \\
\hline 1 & 65 & 81,17 & 7,65 \\
2 & 37 & 76,76 & 7,52 \\
\hline Fonte: elaboração própria & &
\end{tabular}

Como pode ser visualizado na Tabela 3, a "turma da frente" apresentou um CRA médio superior à "turma do fundão". Para confirmar esse achado, utilizou-se o Teste $t$ para analisar a significância estatística dessa diferença. Como primeira etapa à realização do Teste $t$, procedeu-se ao Teste de Levene para verificar a existência de homogeneidade de variância entre os dois grupos estudados, obtendo-se a estatística $\mathrm{F}=0,81 \mathrm{e}$ $p$-valor $=0,37$ para um nível de significância de $5 \%$. Assim, comprovou-se a existência de homogeneidade de variância entre os grupos 1 e 2, dado que a hipótese nula desse teste corresponde à referida igualdade e ela não foi rejeitada, significando que as amostras vêm de populações que possuem variâncias semelhantes (Field, 2009).

Verificada a homogeneidade de variância, prosseguiuse com o Teste $t$ que examinou a existência de igualdade de médias entre os grupos estudados. Os resultados do teste podem ser visualizados na Tabela 4 :
Tabela 4. Teste $t$ para igualdade de médias

\begin{tabular}{cccc}
\hline Estatística t & $\begin{array}{c}\text { Graus de } \\
\text { Liberdade }\end{array}$ & p-valor & $\begin{array}{c}\text { Diferença } \\
\text { Média }\end{array}$ \\
\hline 2,81 & 100 & 0,006 & 4,407 \\
\hline
\end{tabular}

Conforme demonstrado na Tabela 4, a hipótese nula de igualdade das médias dos grupos 1 e 2 foi rejeitada a um nível de significância de 5\%. Sendo assim, os resultados sugerem que, realmente, existe uma diferença positiva de, aproximadamente, 4,41 entre as médias da "turma da frente" em relação à "turma do fundão".

Portanto, de acordo com as evidências levantadas, em relação aos estudantes que se posicionaram mais próximos dos professores durante as aulas, parece terem eles obtido melhor desempenho nas avaliações de aprendizagem e, consequentemente, em seus coeficientes de rendimento acadêmico, considerando-se o grupo de discentes pesquisados.

Possíveis razões para esse resultado podem estar vinculadas a diferenças no comportamento e nível de atenção dos estudantes durante as aulas, e ainda, ao fato de esses estarem mais próximos do campo de visão do docente, ou mesmo por terem a melhor visualização e audição dos conteúdos ministrados, uma vez que, ao se posicionar mais distante de onde o som é emanado e os assuntos são disseminados, a "turma do fundão" encontra barreiras naturais (os colegas sentados à frente e os possíveis ruídos provenientes do ambiente interno e externo à sala de aula) para acessar as informações provenientes dos docentes.

Para melhor entender a relação entre a localização na sala de aula e o desempenho discente, optou-se por realizar uma análise de regressão com o objetivo de correlacionar cada nível de distância entre docente e alunos (mensurado através das médias por fileiras de cadeiras ordenadas na classe) ao desempenho acadêmico dos estudantes (mensurado através dos CRAs). No tópico a seguir, os resultados da análise de regressão são apresentados e discutidos.

\subsection{Análise de regressão}

$\mathrm{Na}$ preparação dos dados para a análise de regressão, realizou-se a comparação dos desempenhos dos estudantes das fileiras à frente em relação aos desempenhos dos estudantes da última fileira. A partir daí, decidiu-se que a última fileira seria representada pela constante no modelo de regressão, que teve como variável dependente os CRAs dos discentes.

Posteriormente, as cadeiras agregadas por fileira, conforme apresentado no mapa presente no questionário de pesquisa (Figura 1), foram transformadas em variáveis dummy. Conforme já explicitado, o estimador escolhido para a regressão foi o de Mínimos Quadrados Ordinários (MQO). A Tabela 5 evidencia os resultados da regressão: 
Tabela 5. Análise de regressão

\begin{tabular}{cccccc}
\hline & B & $\begin{array}{c}\text { Desvio } \\
\text { Padrão }\end{array}$ & t & p-valor & \\
\cline { 1 - 4 } (Constante) & 75,769 & 2,447 & 30,968 &, 000 & $* *$ \\
Fila_1 & 5,342 & 3,023 & 1,767 &, 080 & $*$ \\
Fila_2 & 6,222 & 3,119 & 1,995 &, 049 & $* *$ \\
Fila_3 & 4,998 & 2,825 & 1,769 &, 080 & $*$ \\
Fila_4 & 1,060 & 3,052 & 0,347 &, 729 & \\
Fila_5 & 1,960 & 3,555 & 0,551 &, 583 & \\
\cline { 1 - 3 } $\mathrm{F}=1,644$ & & & & & \\
$\mathrm{R}^{2}=0,079$ & & & & \\
\cline { 1 - 3 }
\end{tabular}

Nota: $\mathrm{N}=102 . * * * \mathrm{p}<0,001, * * \mathrm{p}<0,05, \mathrm{e} * \mathrm{p}<0,10$.

Os resultados da regressão sugerem haver diferença entre o desempenho dos discentes das demais fileiras, quando comparados ao desempenho dos discentes da última fileira. Os betas positivos e significativos, a $5 \% \mathrm{e}$ $10 \%$, relativos a cada uma das três primeiras fileiras da sala de aula, confirmam o resultado do Teste $t$, indicando que os discentes da "turma da frente" apresentaram um desempenho superior aos discentes da última fileira.

Por outro lado, as variáveis que representaram a quarta e quinta fileiras não apresentaram desempenho significativamente diferente dos estudantes da última fileira, mas os seus betas positivos sugerem melhor desempenho, apesar de não serem estatisticamente diferente.

Portanto, pode-se afirmar, a partir dos dados dos testes estatísticos, que, para o grupo estudado, o fato de se sentar mais próximo do docente apresentou uma correlação positiva com o desempenho acadêmico dos discentes, ou seja, a "turma da frente" apresentou melhor CRA do que a "turma do fundão".

$\mathrm{O}$ baixo $\mathrm{R}^{2}$ resultante da regressão é compreensível dado que não é razoável imaginar que o coeficiente de rendimento acadêmico dos discentes possa ser explicado, unicamente, pela localização em que os mesmos preferem se sentar para assistir as aulas. Por conseguinte, pretendeu-se com a regressão apenas testar a existência de associação entre as variáveis.

Faz-se importante destacar que os testes para a verificação da existência de heterocedasticidade, multicolinariedade e da normalidade dos resíduos foram realizados através dos testes de White, do índice de tolerância (TOL) e do fator da variância (FIV) e de Doornik e Hansen, respectivamente, sem que problemas relativos aos pressupostos da regressão fossem encontrados. Adicionalmente, informa-se que os softwares utilizados para a realização do Teste $t$ e da análise de regressão foram o PASW Statistics 17.0 e o gretl 1.9.9, respectivamente.

\subsection{Análise adicional}

Algumas questões de caráter descritivo foram inseridas no questionário de pesquisa, objetivando conhecer a percepção dos discentes quanto à relação entre a localização em sala de aula e o desempenho no curso. A percepção dos estudantes ligada ao seu próprio desempenho e a relação com o local em que o mesmo se senta para assistir às aulas revelam que, para a maioria, existe, sim, uma relação entre as duas variáveis. Isso porque, do total de respondentes, 58,8\% acreditam que o local escolhido para assistir às aulas influencia o desempenho acadêmico, enquanto que $41,2 \%$ não acreditam que esse fato possa provocar interferência no desempenho.

Analisando as respostas relacionadas ao motivo da escolha pelo local da carteira, verificam-se depoimentos que ajudam a explicar o melhor desempenho dos alunos que se sentam mais à frente, em relação aos alunos do "fundão".

Alguns exemplos podem ser citados, como: "é um local tranquilo (frente), onde consigo prestar mais atenção", pressupondo que, mais ao fundo da sala, a capacidade de concentração possa ser comprometida. Outras respostas a essa questão e que ajudam a ilustrar a diferença de desempenho são: "conseguir ouvir melhor a explicação do professor" ou "prestar mais atenção. Falar com o professor, tirar dúvidas".

Já com relação aos alunos do "fundão", verificamse respostas como: "baixa probabilidade de o professor fazer perguntas, é possível fazer outras atividades, caso a aula não esteja interessante" ou "afinidade com os colegas", sugerindo o desenvolvimento de outras atividades paralelas à aula e, ainda, "distância do professor, maior liberdade para conversar", sugerindo uma fuga relacionada à autoridade do professor.

A distância em relação ao professor também foi uma resposta comum entre os respondentes. Algumas repostas chamam a atenção para o fato de que a proximidade entre professor e aluno possa ser um diferencial no desempenho acadêmico do estudante. Segundo os próprios estudantes: "maior proximidade com o professor e melhor visualização do quadro e dos slides" e "maior proximidade com o professor. Rendimento maior. Pouca dispersão".

Outro aspecto que pode ser levado em consideração é o fato de alguns depoimentos corroborarem o preconceito existente em relação aos alunos do "fundão". Algumas respostas, como "presto atenção com mais facilidade no professor. Por causa da conversa do fundão que atrapalha o rendimento" ou "geralmente a turma do fundo conversava muito", podem estar relacionadas a uma possível queda de rendimento entre os alunos do "fundão". 


\section{CONSIDERAÇÕES FINAIS}

O presente estudo teve como finalidade investigar se existe associação entre o desempenho discente no curso de Bacharelado em Ciências Contábeis e a localização escolhida por esses discentes em sala de aula. Foram analisados os Coeficientes de Rendimento Acadêmico de uma amostra composta por 102 observações válidas coletadas em uma instituição pública de ensino superior brasileira.

Os testes estatísticos (Teste $t$ e Regressão) revelaram que, para o grupo estudado, o fato de sentar mais próximo do docente apresentou uma correlação positiva com o desempenho acadêmico dos discentes, ou seja, a "turma da frente" apresentou melhor CRA do que a "turma do fundão". Esses resultados reforçam as afirmativas da literatura (Brandão, 1986) de que existem, de fato, dois grupos na sala de aula (um à frente e outro atrás) e, também, diferenças significativas de desempenho acadêmico entre eles.

Esses achados se constituem em evidências de que o baixo desempenho acadêmico dos discentes do fundão não é um mito, pelo menos para a amostra investigada. No entanto, o estudo não se propôs a explicar as causas dessa diferença. De qualquer forma, algumas pistas sobre esses discentes foram levantadas: a existência de preconceito por parte de professores e alunos (turma da frente); maior distância do campo de visão do docente; maior dificuldade de visualização e audição dos conteúdos ministrados; maior dificuldade de contato com o docente para tirar dúvidas; menor participação nas aulas etc.

Esses resultados são importantes, pois podem servir de base tanto para educadores quanto para instituições de ensino, na geração e adoção de estratégias diferenciadas, de acordo com o perfil de seu alunado no intuito de melhorar o aprendizado e, consequentemente, o rendimento acadêmico, visando um acréscimo da qualidade na formação de profissionais orientados à docência, ou orientados ao mercado de trabalho.

Por outro lado, há que se reconhecer que esta foi uma pesquisa eminentemente exploratória, não tendo, necessariamente, contemplado todas as variáveis possíveis que possam estar relacionadas à diferença de rendimento acadêmico entre a "turma da frente" e a "turma do fundão". Novos estudos são necessários a fim de melhor elucidar a temática. Sugere-se investigar se o aluno se senta no fundo da sala porque tem nota baixa, ou se ocorre o inverso: o aluno tem nota baixa porque se senta no fundo da sala de aula. Pode-se investigar, também, se o preconceito com "a turma do fundão", conforme mencionam Vieira e Maciel (2009), interfere de maneira negativa no desempenho acadêmico, conforme estabelece a abordagem psicológica denominada de "profecia autorrealizável". Finalmente, cabe investigar se existe um tipo de inteligência específica, dentro do escopo das inteligências múltiplas, que melhor represente a "turma do fundão".

\section{REFERÊNCIAS}

Alves, C. V. O, Corrar, L. J., \& Slomski V. A. (2004). Docência e o Desempenho dos Alunos dos Cursos de Graduação em Contabilidade no Brasil. Anais do Congresso USP de Contabilidade e Controladoria, São Paulo, Brasil, 4.

Bernardo, D. C., Nascimento, J. P. B., \& Nazareth, L. G. C. (2010). Representações do Ensino, Pesquisa e Interdisciplinaridade dos Cursos de Ciências Contábeis no Estado de Minas Gerais. Revista de Contabilidade Vista \& Revista, 21 (3), 111-133.

Brandão, C. R. (1986). A turma de trás. In Morais, R. (Org.). Sala de aula: que espaço é esse? CampinasSP: Papirus.

Cardoso, W., Demuner, J. A., \& Batista, G. D. (2006). A Relevância da Interdisciplinaridade para o Ensino dos Métodos Qualitativos nos Cursos de Contabilidade no ES. Anais do Encontro da Anpad, Salvador, Brasil, 30. Recuperado em 03 outubro, 2012, de http://www.fucape.br/public/producao cientifica/2/Cardoso-A \%20Relevancia $\% 20 \mathrm{da} \% 20$ Interdiciplinaridade.pdf

Conselho Federal de Contabilidade. (2012) Exame de Suficiência $3^{a}$ Edição - (1/2012). Recuperado em 07 setembro, 2012, de http://www.cfc.org.br/uparq/ Aprovados_Exame_3_Bacharel_apos_Recursos. pdf

Dayrell, J. (2007). A escola "faz" as juventudes? Reflexões em torno da socialização juvenil. Educação \& Sociedade, 28 (100), 1105-1128.

Field, A. (2009). Discovering statistics using SPSS. 3 ed. Thousand Oaks: Sage.

Figueiredo, S., \& Fabri, P. E. (2000). Gestão de Empresas Contábeis. São Paulo: Atlas.

Freitas, D. S., Ferreira, W. F., \& Ustra, S. R. V. (2011) Investigando Aspectos Motivacionais em Aulas de Física. Recuperado em 20 agosto, 2012, de revistas.jatai.ufg.br/index.php/acp/article/ download/1342/742.

INEP - Instituto Nacional de Estudos e Pesquisas Educacionais Anísio Teixeira. (2010). Censo da Educação Superior 2010: análise crítica dos resultados para a tomada de decisões estratégicas. Recuperado em 13 agosto 2012 de http://www. abmes.org.br/abmes/public/arquivos/documentos/ Christyne e Renan.pdf

Iudícibus, S., \& Marion, J. C. (2002). Introdução à teoria da contabilidade para o nivel de graduação. 3. ed. São Paulo: Atlas. 
Kaya, N., \& Burgess, B. (2007). Territoriality: Seat Preferences in Different Types of Classroom Arrangements. Environment and Behavior. 39 (6), 859-876.

Kennedy, P. (2008). A guide to econometrics. 6 ed. Malden: Blackwell.

King, B. M., Rosopa, P. J., \& Minium, E. W. (2011). Statistical reasoning in the behavioral sciences. 6 ed. Danvers: John Wiley \& Sons.

Laffin, M. (2005). De Professor a Contador: A trajetória da Docência no Ensino Superior de Contabilidade. Florianópolis: Imprensa Universitária.

Lousada, A. C. Z., \& Martins, G. A. (2005). Egressos como Fonte de Informação à Gestão dos Cursos de Ciências Contábeis. Revista Contabilidade \& Finanças, 16 (37), 73-83.

Miranda, G. J. (2011). Relações entre as qualificações do professor e o desempenho discente nos cursos de graduação em Contabilidade no Brasil. Tese de doutorado em Ciências Contábeis, Programa de PósGraduação em Ciências Contábeis, Departamento de Contabilidade e Atuária, FEA/USP, São Paulo, Brasil.

Miranda, G. J., Casa Nova, S., \& Cornacchione, E. (2012). Ao Mestre com Carinho: Relações entre as Qualificações Docentes e o Desempenho Discente em Contabilidade. Anais do Congresso da ANPCONT, Blumenau, Brasil, 6.

Moraes, V. F. M. J., \& Araujo, A. O. (2012). Avaliação da Aprendizagem: Uma Experiência do Uso do Portfólio em uma Disciplina do Curso de Ciências Contábeis. Revista Ambiente Contábil, 4 (1), 36-50.

Montello, D. R. (1988). Classroom seating location and its effect on course achievement, participation, and attitudes. Journal of Environmental Psychology, 8 (2), 149-157.

Paiva, V. (1993). Novo paradigma de desenvolvimento: educação, cidadania e trabalho. Revista de Ciência da Educação, Educação e Sociedade, 14 (45), 309323.

Pedersen, D. M. (1994). Privacy preferences and classroom seat selection. Social Behavior and Personality: an international journal, 22 (4), 393398.

Peleias, I. R., Silva, G. P., Segreti, J. B., \& Chirotto, A. R. (2007). Evolução do ensino da contabilidade no Brasil: uma análise histórica. Revista Contabilidade e Finanças, 18, n.spe, 19-32.

Silva, A. C. R., Gomes, S. M., \& Guimarães, I. P. (2008). Educação em Contabilidade: Alguns Aspectos Crítico Sugestivos do Exame Nacional de Desempenho dos Estudantes. Anais do Congresso Brasileiro de Contabilidade, Gramado, Brasil, 18.

Silva, D. J. C., Ranciaro Neto, A., Anjos, L. C. M., \& Miranda, L. C. (2012). Redes Sociais e o
Desempenho Acadêmico: Um estudo com Alunos de Contabilidade. Anais do Encontro Nacional dos Cursos de Pós-Graduação em Administração, Rio de Janeiro, Brasil, 36.

Silva. I. I. (2006). Ressignificando as Identidades no Ensino-Aprendizagem de Língua Inglesa em uma Escola da Rede Estadual. Dissertação de Mestrado em Linguística Aplicada e Estudos da Linguagem, Pontifícia Universidade Católica de São Paulo, São Paulo.

Souza, E. S. (2008). ENADE 2006: Determinantes do Desempenho dos Cursos de Ciências Contábeis. Dissertação de Mestrado em Ciências Contábeis, Universidade de Brasília, Brasília.

Stires, L. (1980). Classroom Seating Location, Student Grades, and Attitudes: Environment or SelfSelection? Environment and Behavior, 12 (2), 241254.

Totusek, P. F., \& Staton-Spicer, A. Q. (1982). Classroom seating preference as a function of student personality. The Journal of Experimental Education, 50 (3), 159-163.

Vieira, R. A., \& Maciel, L. S. B. (2009). A Turma de Trás: Preconceito e Exclusão aos Alunos do "fundão". Periódico do Mestrado em Educação da UCDB, 1 (28), 11-20.

Waiselfisz, J. (2000). Qualidade e recursos humanos nas escolas. Brasília: Fundescola - MEC. 